\title{
Reversed phase HPLC determination of zidovudine in rat plasma and its pharmacokinetics after a single intranasal dose administration
}

\author{
RUBIANA M. MAINARDES ${ }^{1, *}$ and MARIA PALMIRA D. GREMIÃO ${ }^{2}$ \\ ${ }^{1}$ Departamento de Farmácia, Universidade Estadual do Centro-Oeste/UNICENTRO - Guarapuava-PR, Brazil. \\ ${ }^{2}$ Departamento de Fármacos e Medicamentos, Faculdade de Ciências Farmacêuticas, Universidade Estadual \\ Paulista Júlio de Mesquita Filho/UNESP, Araraquara-SP, Brazil.
}

\begin{abstract}
The development and validation of a simple and accurate method based on HPLC with ultraviolet detection for the quantification of zidovudine in rat plasma and its application to a pharmacokinetic study following a single intranasal dose zidovudine is described. Zidovudine was extracted from the plasma using a single-step deproteinization. Chromatographic separation of zidovudine from interfering components was achieved with a $\mathrm{C}-18$ reverse phase column, a mobile phase consisting of a mixture of sodium acetate buffer $(55 \mathrm{mM}) \mathrm{with} \mathrm{pH}$ adjusted to 7.0 and acetonitrile $(91: 9 \mathrm{v} / \mathrm{v})$ and UV detection set at $265 \mathrm{~nm}$. The method was linear from 100 to $10000 \mathrm{ng} \cdot \mathrm{mL}^{-1}\left(\mathrm{r}^{2} \geq 0.9995\right)$, and zidovudine had a mean recovery from plasma of $92.8 \%$. The coefficient of variation of inter-day and intra-day quality control samples was less than $15 \%$. After a single intranasal dose of zidovudine administered to rats, pharmacokinetic parameters $\left(\mathrm{AUC}_{0-24}, \mathrm{C}_{\max }, \mathrm{t}_{\max }, \mathrm{t}_{1 / 2}\right)$ were determined. The proposed method was found to be simple, specific, accurate, and precise and could be applied to the quantitative analysis of clinical pharmacokinetic studies of zidovudine in rats.
\end{abstract}

Key terms: RP-HPLC, validation, AZT, pharmacokinetics, intranasal delivery.

\section{INTRODUCTION}

Since it was first recognized in 1981, the Acquired Immunodeficiency Syndrome (AIDS) has been a major public health problem. Zidovudine (3'-azido-3'deoxythymidine, AZT), the first anti-HIV compound approved for clinical use (Yarchoan et al., 1989; Chien and Wearley, 1989) is still widely used for antiretroviral therapy in combination with other antiretroviral agents (Clerq, 2004).

Oral AZT has a short elimination halflife and low bioavailability, and frequent high doses are required to maintain the therapeutic level (Blum et al., 1988; Mandal and Tenjarla, 1996). As a result, dose-dependent toxic side effects are frequently observed (Oh et al., 1998;
Thomas and Panchagnula, 2003). To avoid the serious toxic effects resulting from oral administration, an intranasal route for AZT delivery has been proposed.

Analytical methods employed for the quantitative determination of drugs and their metabolites in biological samples play a significant role in evaluation and interpretation of bioavailability, bioequivalence and pharmacokinetic data. It is essential to employ well-characterized and fully validated analytical methods to yield reliable results that can be successfully interpreted (Shah et al., 1992).

The validation of an analytical method must guarantee that it fulfills all the requirements of the analytical applications, assuring the security of the results. For this reason, it must present specificity, linearity,

\footnotetext{
* Corresponding author: Rubiana Mara Mainardes, Departamento de Farmácia, Universidade Estadual do Centro-Oeste, Rua Simeão Camargo Varela de Sá n. 03, Guarapuava - PR, Brazil 85040-080, Telephone: +55-42 36298137; Fax: +55-4236298102,E-mail address: rubianamainardes@hotmail.com
} 
precision, sensitivity, accuracy and limit of quantification adjusted to the analyses (USP, 2004; ANVISA, 2003; British Pharmacopoeia, 2001; ICH, 2005).

A number of analytical methods have been reported for determination of AZT in human and animal biological fluids and tissue organ extracts. These methods involve ultraviolet assay (Baig et al., 2001; Erk, 2004), liquid chromatography/tandem mass spectrometry (Kenney et al., 2000; Pereira et al., 2000; Alnouti et al., 2005; Mudigonda et al., 2008), micellar capillary electrophoresis (Alnouti et al., 2004) and high-performance liquid chromatography (HPLC) with UV detection (Molema et al., 1992; Schrive and Plasse, 1994; Aymard et al., 2000; Tan and Boudinot, 2000; Clark et al., 2001; Marchei et al., 2002; Alnouti et al., 2004; Ramachandran et al., 2006; Tarinas et al., 2007; Lewis et al., 2007; Lefebvre et al., 2007). Most of the methods using HPLC with UV detection methods described until now are relatively timeconsuming or they use expensive instrumentation not readily accessible to many groups. Furthermore, the use of solid phase extraction or several steps of liquidliquid extraction increases the total cost of the analysis, especially when a large number of samples is analyzed. Thus, the need for a time and cost-saving method conforming to the current guidelines for the analysis of AZT in plasma stimulated us to investigate the usefulness of a new simple and fast method with adequate sensitivity and selectivity to perform the quantification of AZT in rat plasma.

This paper describes the development and validation of a rapid and efficient HPLC method for AZT quantification in rat plasma and its application in a pharmacokinetic study in rats using the intranasal route.

\section{METHODS}

\section{Drugs and Chemicals}

The organic HPLC grade solvents used for extraction and mobile phase preparation were purchased from Malinkrodt (São
Paulo, SP, Brazil). All other reagents were analytical grade. AZT was a gift from "Fundação para o Remédio Popular" (FURP, São Paulo, Brazil). Sodium thiopental was purchased from Cellofarm Ltda (Rio de Janeiro, RJ, Brasil). The ultrapure water was prepared in a Milli-Q system (Millipore, Molsheim, France). Blank rat blood was collected from healthy, drug-free rats. Plasma was obtained by centrifugation of blood treated with anticoagulant. Plasma was prepared and stored at approximately $-20{ }^{\circ} \mathrm{C}$.

\section{Instruments and chromatographic conditions}

A high pressure liquid chromatography (HPLC) Varian ProStar 330 system was used. This system was composed of a controlled system, manual injector with a $100 \mu \mathrm{L}$ loop and a UV-Visible detector at $265 \mathrm{~nm}$. A reversed-phase Lichrospher C18 column $(240$ x $4 \mathrm{~mm}$ i.d., pore size $5 \mu \mathrm{m})$ was used. The mobile phase consisted of a mixture of sodium acetate buffer $(55 \mathrm{~mm})$ with $\mathrm{pH}$ adjusted at 7.0 and acetonitrile (91: $9 \mathrm{v} / \mathrm{v})$. The flow rate was set at $1 \mathrm{ml} \cdot \mathrm{min}^{-1}$ and a $100 \mu \mathrm{l}$ aliquot was injected into the HPLC column. Peaks were monitored at $265 \mathrm{~nm}$. All chromatographic experiments were carried out in the isocratic mode. The performance of the methodology was evaluated by using standard solutions of the compounds. After subsequent analysis of the results, the methodology was optimized using plasma samples for posterior in vivo studies.

\section{Standard solutions}

The AZT was weighed and dissolved in bidistilled water at room temperature to obtain a stock solution of $1.0 \mathrm{mg} \cdot \mathrm{mL}^{-1}$. Serial dilutions of the stock solutions were made for spiking the calibration standards. The calibration curve for AZT was prepared in rat plasma at seven concentrations: 100, $500,1000,2000,4000,5000$ and 10000 ng. $\mathrm{mL}^{-1}$. The simulated samples were prepared by adding appropriate volumes of the diluted solutions to drug-free rat plasma. Stock and working standard 
solutions were protected from light and stored at $-20{ }^{\circ} \mathrm{C}$ until used.

\section{Sample preparation}

To determine AZT in rat plasma, blood samples were taken the from tail vein and placed in tubes containing sodium heparin. The tubes were centrifuged $(850 \mathrm{~g}$ for 20 $\min )$ at $27^{\circ} \mathrm{C}$ in order to separate the plasma elements and stored at $-20{ }^{\circ} \mathrm{C}$ for posterior analysis. In order to ensure the effective separation of AZT from plasma components, the deproteinization method was used. One (1) $\mathrm{mL}$ of acetronitrile was added to $100 \mu \mathrm{L}$ of plasma. The mixture was vortex-mixed for $1 \mathrm{~min}$ and centrifuged for $15 \mathrm{~min}$ at $1600 \mathrm{~g}$. The supernatant was transferred to a tube and evaporated to dryness (approximately $15 \mathrm{~min}$ ), under a stream of nitrogen. The resulting residue was reconstituted in $200 \mu \mathrm{L}$ of the mobile phase.

\section{Assay validation}

To validate the assay in rat plasma, the following parameters were investigated: selectivity, linearity, precision and accuracy, limit of quantification, limit of detection and recovery (ANVISA, 2003; British Pharmacopoeia, 2001; ICH, 2005).

\section{Selectivity}

Selectivity is defined as the lack of interfering peaks at the retention times of the assayed drug. The specificity of the method was determined by comparing the chromatograms obtained from the samples containing AZT with those obtained from blank plasma samples.

\section{Recovery and linearity}

In the analysis of AZT in rat plasma, the analytical recovery of AZT was determined at concentrations of 150,500 and 1000 $n g \cdot \mathrm{mL}^{-1}(\mathrm{n}=3)$. Samples of the plasma without drug were spiked with known amounts of the drug to achieve the specified concentration. These samples were processed by the analytical method described above and peak areas were compared to that obtained by direct injection of the drug in the mobile phase. To calculate linearity, calibrations curves were constructed by linear regression within the range of $100-10000 \mathrm{ng} \cdot \mathrm{mL}^{-1}$ of AZT, by using seven standard solutions.

The limit of quantification (LOQ) was determined as the lower value in the calibration curve. The limit of detection (LOD) (equation 1) was mathematically determined from the ratio of the mean of the standard deviations (MSD) of various analytical sample responses and the slope of the calibration curve, using the appropriate enhancement factors suggested by "International Conference on Harmonization" (ICH, 2005). For the LOD, three samples at concentrations near to the smallest concentration of the standard curve (triplicate) were analyzed in order to obtain the standard deviations and to calculate the MSD (USP, 2004; ANVISA, 2003; British Pharmacopoeia, 2001; ICH, 2005).

$$
L O D=\frac{3 . \mathrm{MSD}}{\text { slope }}
$$

\section{Precision and accuracy}

Precision was determined as the coefficient of variation (CV) and accuracy as the percent relative error (RE). Intraday precision and accuracy data were obtained by analyzing aliquots of plasma samples at low (150 ng.mL ${ }^{-1}$ ), medium (500 ng.mL ${ }^{-1}$ ) and high (1000 ng.mL $\mathrm{m}^{-1}$ ) levels of the AZT concentration $(n=5)$. Inter-day reproducibility was determined over three days.

\section{Pharmacokinetic study}

The analytical method was applied to evaluate the pharmacokinetic parameters of AZT after its intranasal administration in rats.

Male adult Wistar rats $(n=6)$ with a mean body weight of $190 \pm 10 \mathrm{~g}$ were fasted overnight prior to the experiments, with free access to water. Rats were anesthetized by intraperitoneal injection of sodium thiopental at a dose of $50 \mathrm{mg} \cdot \mathrm{kg}^{-1}$. The AZT 
aqueous solution (160 $\left.\mu \mathrm{g} \cdot \mathrm{mL}^{-1}\right)$ was administered intranasally by instilling, through a cannula, $100 \mu \mathrm{L}$ into each nostril (20 $\mu \mathrm{L}$, five times in 4-minute intervals). This spaced instillation was intended to allow the administration of a high dose of particles and minimize the overflow into the gastrointestinal tract. The blood samples $(300 \mu \mathrm{L})$ were withdrawn from the tail vein of the rats at 0 (pre-dose) and $0.5,1,2,3,4$, $5,6,7,8,9,10$ and $24 \mathrm{~h}$ postadministration. Since there were no data in the literature about AZT bioavailability by the intranasal route, it was necessary to perform the analysis within $24 \mathrm{~h}$. The blood samples were then centrifuged $(15 \mathrm{~min}$ at $8500 \mathrm{~g}$ ), and $100 \mu \mathrm{L}$ of each plasma sample was used for the HPLC assay, as previously described. The study was previously approved by the committee of ethics of the Faculdade de Ciências Farmacêuticas de Araraquara, Brazil.

\section{Data analysis}

Maximum observed plasma concentration $\left(\mathrm{C}_{\max }\right)$ and the time taken to reach it $\left(t_{\max }\right)$ were obtained from the plot of drug concentration vs. time.

The area under the AZT concentrations vs. time curve from $0-24 \mathrm{~h}\left(\mathrm{AUC}_{0-24 \mathrm{~h}}\right)$ was calculated by the trapezoidal rule and the first-order elimination rate constant $\left(\mathrm{K}_{\mathrm{e}}\right)$ was estimated by least-squares regression of the points describing the terminal loglinear decaying phase. The $t_{1 / 2}$ were derived from $K_{e}\left(t_{1 / 2}=\ln _{2} / K_{e}\right)$.

\section{Statistical analysis}

The result was expressed as mean \pm standard deviation (S.D).

\section{RESULTS}

Figure 1 shows chromatograms of the blank rat plasma, blank rat plasma spiked with AZT and rat plasma obtained $8 \mathrm{~h}$ after intranasal AZT administration. The retention time for AZT was $12.7 \mathrm{~min}$, at a flow rate of $1.0 \mathrm{~mL} \cdot \mathrm{min}^{-1}$. The described method was shown to be selective for the analyte.
The calibration curve for AZT was constructed by plotting the area under peak versus drug concentration. It was found to be linear over a concentration range (100 10000 ng.mL $\left.{ }^{-1}\right)$. Table I shows data from calibration curves prepared throughout the application of the method. Each point was analyzed in triplicate. The mean correlation coefficient was 0.9995 .

The LOD in plasma was determined by analysis of standard-spiked samples gradually decreasing in concentration. The LOQ was considered as the lower concentration value obtained in the calibration curve. The LOD and LOQ were 30.01 and $100 \mathrm{ng} . \mathrm{mL}^{-1}$, respectively.

The mean absolute recovery of AZT in rat plasma was $92.8 \pm 1.49 \%$. The results indicate a lack of interference from the sample preparation procedure. The analytical precision and accuracy for intraday $(n=5)$ and inter-day $(n=3)$ assays of three quality controls $(150,500$ and 1000 $\left.\mathrm{ng} . \mathrm{mL}^{-1}\right)$ are presented in Table II.

Mean AZT plasma concentration-time profiles and mean values of pharmacokinetic parameters after intranasal administration of AZT in healthy rats are shown in Figure 2 and Table III, respectively.

\section{DISCUSSION}

The HPLC methods described in the literature for determination of AZT levels in animal and human plasma (Molema et al., 1992; Schrive and Plasse, 1994; Aymard et al., 2000; Tan and Boudinot, 2000; Clark et al., 2001; Marchei et al., 2002; Alnouti et al., 2004; Ramachandran et al., 2006; Tarinas et al., 2007; Lewis et al., 2007; Lefebvre et al., 2007) present high analysis costs of because they use sample treatment processes based on solid phase extraction or several steps of liquid-liquid extraction. These assay methods are relatively time-consuming or use expensive instrumentation not readily accessible to many groups. Therefore, our goal was to develop a relatively rapid and low-cost assay that could be performed at any laboratory with adequate HPLC instrumentation. 

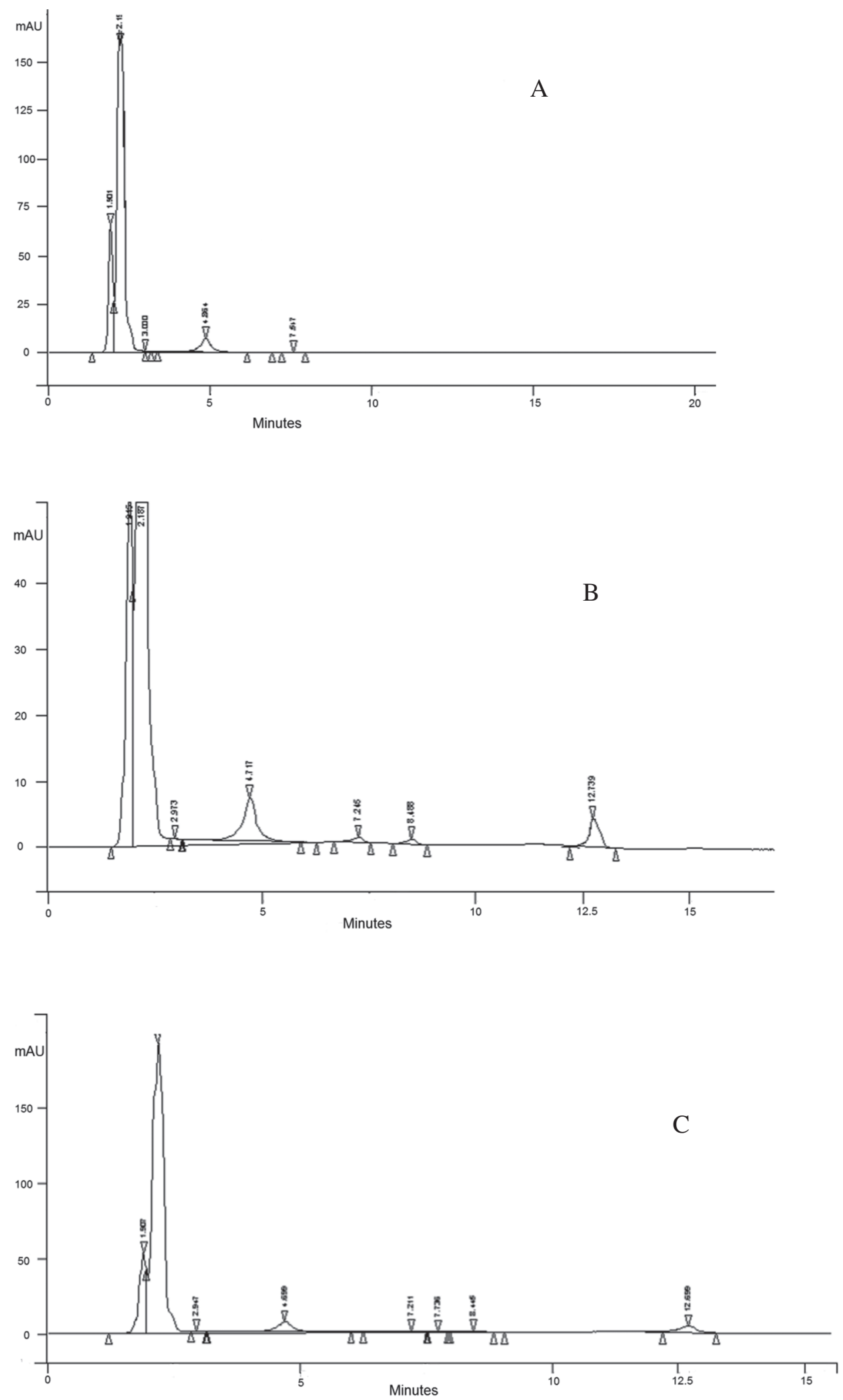

Figure 1: Chromatograms demonstrating selectivity: A) blank rat plasma, B) blank rat plasma spiked with AZT (500 ng. $\left.\mathrm{mL}^{-1}\right), \mathrm{C}$ ) plasma from rat $8 \mathrm{~h}$ after intranasal administration of AZT. 


\section{TABLE I}

The precision and accuracy of points of the calibration curve.

\begin{tabular}{lccc}
\hline Nominal value $\left(\mathrm{ng} . \mathrm{mL}^{-1}\right)$ & $\begin{array}{c}\text { Observed value }\left(\mathrm{ng} . \mathrm{mL}^{-1}\right) \\
\left(\mathrm{ng} . \mathrm{mL}^{-1}\right)(\text { Average } \pm \mathrm{SD})(\mathrm{n}=3)\end{array}$ & Precision (\%) & Accuracy (\%) \\
\hline 100 & $108.01 \pm 9.0$ & 8.34 & 108.01 \\
500 & $522.95 \pm 14.85$ & 2.84 & 104.59 \\
1000 & $940.96 \pm 21.83$ & 2.32 & 94.09 \\
2000 & $1939.83 \pm 75.04$ & 3.87 & 96.99 \\
4000 & $3919.07 \pm 10.55$ & 2.70 & 97.95 \\
5000 & $4853.38 \pm 421.27$ & 8.68 & 97.06 \\
10000 & $10116.79 \pm 687.94$ & 6.80 & 101.16 \\
\hline
\end{tabular}

TABLE II

Intra- and interday precision and accuracy of AZT in rat plasma.

\begin{tabular}{lccc}
\hline Nominal value $\left(\mathrm{ng} . \mathrm{mL}^{-1}\right)$ & Observed value $\left(\mathrm{ng} \cdot \mathrm{mL}^{-1}\right)$ & Precision $(\%)$ & Accuracy $(\%)$ \\
\hline Intraday $(\mathrm{n}=5)$ & & & \\
150 & $160.74 \pm 3.60$ & 2.24 & 107.16 \\
500 & $587.41 \pm 8.63$ & 1.47 & 117.48 \\
1000 & $936.69 \pm 21.62$ & 2.31 & 93.67 \\
& & & \\
Interday $(\mathrm{n}=3)$ & & 3.89 & 107.15 \\
150 & $163.46 \pm 6.35$ & 4.24 & 93.15 \\
500 & $465.78 \pm 19.74$ & 1.78 & 93.67 \\
1000 & $936.72 \pm 16.67$ & &
\end{tabular}

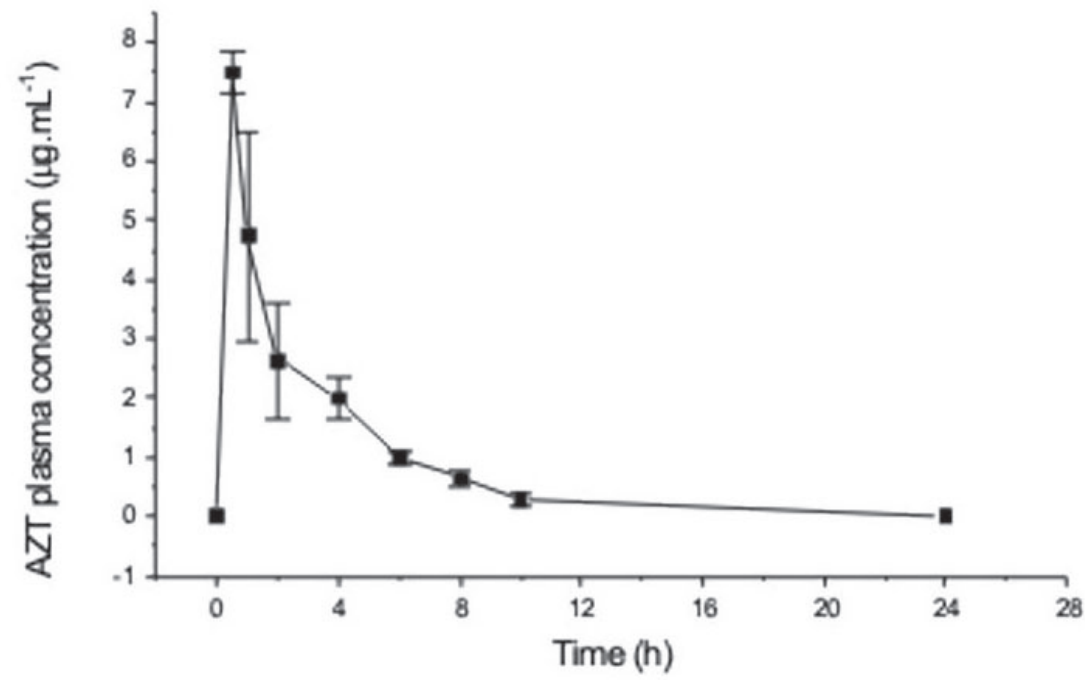

Figure 2: AZT plasma concentration-versus-time after intranasal administration $(\mathrm{n}=6)$ 


\section{TABLE III}

Pharmacokinetic parameters after a single intranasal dose of AZT in rats $(n=6)$.

\begin{tabular}{lc}
\hline Pharmacokinetic parameters & Mean $\pm \mathrm{SD}(\mathrm{n}=6)$ \\
\hline $\mathrm{AUC}_{0-24 \mathrm{~h}}(\mu \mathrm{g} \cdot \mathrm{min} / \mathrm{mL})$ & $1126.8 \pm 129.2$ \\
$\mathrm{C}_{\max }\left(\mu \mathrm{g} \cdot \mathrm{mL}^{-1}\right)$ & $7.5 \pm 0.3$ \\
$\mathrm{t}_{\max }(\min )$ & 30 \\
$\mathrm{~K}_{\mathrm{e}}\left(\mathrm{h}^{-1}\right)$ & 0.4739 \\
$\mathrm{t}_{1 / 2}(\mathrm{~h})$ & 1.46 \\
\hline
\end{tabular}

The reversed-phase HPLC-UV method described, validated and used for AZT quantification, provides adequate sensitivity, specificity and high sample throughput required for pharmacokinetic studies.

The chromatograms showed a good baseline separation and the mobile phase used resulted in optimal separation. The method was selective for AZT since it shows that no interfering peaks appeared near the retention time of the compound of interest. The LOQ and LOD values were low, indicating the good sensitivity of this HPLC method.

The precision met the expected range. The coefficient of variation did not exceed $15 \%$ in the analyses and considered acceptable according to the regulatory agency responsible for health surveillance in Brazil (ANVISA, 2003). Accuracy and recovery were also in good agreement with acceptable values for the validation of an analytical procedure $(100 \pm 20 \%)$.

The validated method was employed in pharmacokinetic analysis of AZT after a single intranasal administration in rats. AZT was well tolerated at the dose used and no adverse effects were reported. The AZT aqueous solution was absorbed quickly after intranasal administration and the maximum plasmatic concentration of approximately $7.5 \mu \mathrm{g} \cdot \mathrm{mL}^{-1}$ in $30 \mathrm{~min}$ was achieved. Thereafter, the AZT plasmatic concentration decreased abruptly, as it is rapidly metabolized, resulting in a short $\mathrm{t}_{1 / 2}$. Hours after intranasal administration, the AZT was still detected $\left(0.27 \mu \mathrm{g} . \mathrm{mL}^{-1}\right)$, but it is not detectable after $24 \mathrm{~h}$. The AZT shows short $\mathrm{t}_{1 / 2}(\sim 1.46 \mathrm{~h})$, in accordance with the literature (Blum et al., 1988, Yarchoan et al., 1989).

The HPLC method used here proved to be simple, fast, reliable, selective and sensitive enough to be used in clinical pharmacokinetic studies of AZT in rats. The method was capable of determining concentrations of AZT in small volumes of rat plasma.

The sample preparation used in this study involved only a single step, i.e., deproteinization with acetonitrile. This condition was optimal for sample preparation as it resulted in clean chromatograms.

Considering the fact that the present method involves a shorter running time and simpler equipment and sample preparation than available methods, it may be used in similar studies as rapid and cost effective alternative to other available methods.

\section{ACKNOWLEGMENTS}

This study was supported by Fundação para o Amparo à Pesquisa do Estado de São Paulo (FAPESP), Brazil. (05/50994-6).

\section{REFERENCES}

ALNOUTI Y, LEWIS SR, WHITE CA, BARTLETT MG (2005) Simultaneous determination of zidovudine and lamivudine from rat tissues by liquid chromatography/ tandem mass spectrometry. Rapid Commun Mass Spectrom 19: 503-508

ALNOUTI Y, WHITE CA, BARTLETT MG (2004) Simultaneous quantitation of zidovudine and zidovudine monophosphate from plasma, amniotic fluid and tissues by micellar capillary electrophoresis. Biomed Chromatogr 18: 523-531

ALNOUTI Y, WHITE CA, BARTLETT MG (2004) Simultaneous determination of zidovudine and lamivudine from rat plasma, amniotic fluid and tissues by HPLC. Biomed Chromatogr 18: 641-647

ANVISA. Agência Nacional de Vigilância Sanitária (ANVISA). Resolução RE $\mathrm{n}^{\circ}$ 899, de 29 de maio de 2003. Diário Oficial da União, Brasília, DF, 02 Maio 2003

AYMARD G, LEGRAND M, TRICHEREAU N, DIQUET B (2000) Determination of twelve antiretroviral agents in human plasma sample using reversed-phase highperformance liquid chromatography. J Chromatogr B: Biomed Sci Appl 744: 227-240

BAIG MV, GAPSE GS, RAJU SA (2001). Spectrophotometric Determination of Lamivudine. Asian J Chem 13: 185-189 
BLUM MR, LIAO SHT, GOOD SS, MIRANDA P (1988). Pharmacokinetics and bioavailability of zidovudine in humans. Am. J. Med 85: 189-194

BRITISH PHARMACOPOEIA. LONDON: THE STATIONERY OFFICE, 2001. v. 2, p.A437-A8

CHIEN YW, WEARLEY LL (1989) Aids and chemotherapy. Drugs of Today 25: 19-25

CLARK TN, WHITE CA, CHU CK, BARTLETT MG (2001) Determination of 3'-Azido-2',3' Dideoxyuridine (AZDU) in Maternal Plasma, Amniotic Fluid, Fetal and Placental Tissues by High Performance Liquid Chromatography. J Chromatog B: Biomed Sci Appl 755: 165-172

CLERQ ED (2004) Antiviral drugs in current clinical use. J Clin Virol 30: 115-133

ERK N (2004) Derivative-differential UV spectrophotometry and compensation technique for the simultaneous determination of zidovudine and lamivudine in human serum. Pharmazie 59: 106-111

International Conference on Harmonisation (ICH); Validation of Analytical Procedures: Text and Methodology, Q2 (R1), 2005

KENNEY KB, WRING SA, CARR RM, WELLS GN, DUNN JA (2000) Simultaneous determination of zidovudine and lamivudine in human serum using HPLC with tandem mass spectrometry. J Pharm Biomed Anal 22: 967-983

LEFEBVRE I, PUY JY, PERRIN C, PÉRIGAUD C (2007) Quantification of zidovudine and its monophosphate in cell extracts by on-line solid-phase extraction coupled to liquid chromatography. J Chromatog B: Anal Tech Biomed Life Sci 858: 2-7

LEWIS SR, WHITE CA, BARTLETT MG (2007) Simultaneous Determination of Abacavir and Zidovudine From Rat Tissues Using HPLC With Ultraviolet Detection. J Chromatog B 850: 45-52. J Chromatog B: Anal Tech Biomed Life Sci 850: 45-52

MANDAL TK, TENJARLA S (1996) Preparation of biodegradable microcapsules of zidovudine using solvent evaporation: Effect of the modification of aqueous phase. Int J Pharm 137: 187-197

MARCHEI E, VALVO L, PACIFICI R, PELLEGRINI M, TOSSINI G, ZUCCARO P (2002) Simultaneous determination of zidovudine and nevirapine in human plasma by RP-LC. J Pharm Biomed Anal 29: 10811088

MOLEMA G, JANSEN RW, VISSER J, MEIJER DK (1992) Simultaneous analysis of azidothymidine and its mono-, di- and triphosphate derivatives in biological fluids, tissue and cultured cells by a rapid highperformance liquid chromatographic method. J Chromatog 579: 107-114
MUDIGONDA K, JUKANTI R, APTE SS, KISHAN V, MAURYA S, KANDIKERE V, NIROGI R (2008) Rapid and simple liquid chromatography tandem mass spectrometry method for the quantification of zidovudine in rat plasma. Biomed Chromatog 22: 20-27

OH, SY, JEONG SY, PARK TG, LEE JH (1998) Enhanced transdermal delivery of AZT (Zidovudine) using iontophoresis and penetration enhancer. J Control Release 51: 161-168

PEREIRA AS, KENNEY KB, COHEN MS, HALL JE, ERON JJ, TIDWELL RR, DUNN JA (2000) Simultaneous determination of lamivudine and zidovudine concentrations in human seminal plasma using high-performance liquid chromatography and tandem mass spectrometry. J Chromatog B: Biomed Sci Appl 742: 173-183

RAMACHANDRAN G, HEMANTHKUMAR AK, KUMARASWAMI V, SWAMINATHAN S (2006) A simple and rapid liquid chromatography method for simultaneous determination of zidovudine and nevirapine in plasma. J Chromatog B: Anal Tech Biomed Life Sci 843: 339-344

SCHRIVE I, PLASSE JC (1994) Quantification of zidovudine and one of its metabolites in plasma and urine by solid-phase extraction and highperformance liquid chromatography. J Chromatog B: Biomed Sci Appl 657: 233-237

SHAH VP, MIDHA KK, DIGHE S, MC GILVERAY IJ, SKELLY JP, YACOBI A et al (1992) Analytical methods validation: Bioavailability, bioequivalence and pharmacokinetic studies. Int J Pharm 82: 1-7

TAN X, BOUDINOT FD (2000) Simultaneous determination of zidovudine and its monophosphate in mouse plasma and peripheral red blood cells by highperformance liquid chromatography. J Chromatog B: Biomed Sci Appl 740: 281-287

TARINAS A, TÁPANES, RD, FERRER, G, PÉREZ, J (2007) Validation of high-performance liquid chromatography methods for determination of zidovudine, stavudine, lamivudine and indinavir in human plasma. Farm Hosp 31: 243-247

THOMAS NS, PANCHAGNULA R (2003) Transdermal delivery of zidovudine: effect of vehicles on permeation across rat skin and their mechanism of action. Eur J Pharm Sci 18: 71-79

USP. United States Pharmacopeia. 27th. ed. Rockville: United States Pharmacopeial Convention, 2004. p. 2622-2625

YARCHOAN R, MITSUYA H, MYERS CE, BRODER S (1989) Clinical pharmacology of 3'-azido-2,3dideoxythymidine (zidovudine) and related dideoxynucleosides. New Engl J Med 321: 726-738. 